\title{
Assessment of role of Integrated Counselling and Testing Centre in addressing HIV/AIDS stigma
}

\author{
Suneetha Pendyala (BPhty, MPH,) (Research Assistant)*, Melissa Glenda Lewis (Msc, PhD,) \\ (Assistant Professor) \\ Indian Institute of Public Health, Hyderabad, India
}

\section{A R T I C L E I N F O}

\section{Keywords:}

HIV

AIDS

Stigma

ICTC

\begin{abstract}
A B S T R A C T
Objective: To assess the stigma among HIV patients and to assess the role of Integrated Counselling and Testing Centre in addressing HIV/AIDS stigma.

Methods: Mixed method study design was conducted at Government General Hospital, Guntur Andhra Pradesh. HIV patients visiting the ICTC centre and the counsellors were included in the study. Patients were interviewed about stigma (quantitative questionnaire created using the International Centre for Research on Women guidelines). In-depth interviews were conducted among the medical officer and counsellors.

Results: Stigma among HIV patients were categorized into six domains; they are social judgment, anticipated stigma, internalized stigma, external stigma, discrimination resilience. Internalized stigma was prevalent among the patients. The percentage of patients aware of ICTC services was $96.30 \%$. Counselling provided by the counselors was useful in addressing stigma among the patients.

Conclusion: Anti-stigma campaigns are essential to tackle internalized stigma among people living with HIV and to incorporate counselling to the family members of HIV patients.
\end{abstract}

\section{Introduction}

The third largest HIV epidemic throughout the world is India. According to National Aids Control organization (NACO) and UNAIDS estimates 2017, the prevalence of adult HIV in India was $0.22 \%{ }^{1}$ Guntur has the highest number of HIV positive cases and the registered cases during 2013-2014 (5,195, including 2498 female). ${ }^{2}$ According to World Health Organization by the end of 2018, people living with HIV were approximately 37.9 million, among which $62 \%$ had access to antiretroviral therapy and 8.1 million of people with HIV did not know that they have HIV. 24.5 million People living with HIV were accessing antiretroviral therapy in June 2019. The virus that infects the cells of the immune system by impairing or destroying their function is Human Immunodeficiency Virus (HIV). Acquired Immunodeficiency Syndrome (AIDS) is the most advanced stage of HIV and is defined by the occurrence of 20 opportunistic infections. ${ }^{3}$ Stigma is a social construction which affects the life experiences of people infected with HIV, their partners, family, and friends. This also affects self-esteem and disrupts a family relationship. The leading cause of discrimination and exclusion is stigma. ${ }^{4}$ In any government district hospitals, Integrated Counselling and Testing Centre's (ICTC) are located. The primary functions of ICTC include, diagnostic tests, provides information on the modes of transmission of HIV, behavioral change promotion to reduce vulnerability and treatment services. ${ }^{5}$

A study was conducted in 2012 at Maharashtra to examine the HIV related stigma in the tribal and rural community in which they concluded that silence, fear, and denial was contributing to stigma among HIV + patients. ${ }^{6}$ Studies in Mumbai and Bangalore found that internalized and enacted stigma was correlated with delays in seeking care after testing HIV + and it was essential to develop stigma reduction interventions to ensure timely receipt of care. ${ }^{7}$ Dasgupta et al. (2013) concluded that stigma was prevalent among HIV positive infected women in West Bengal. Also, the authors emphasized that stigma should be explored and must be given importance. ${ }^{8}$ Parker R, Aggleton $P$ conducted a study on HIV and AIDS-related stigma and discrimination and in that study they mentioned a conceptual frame work and implications for action on HIV and AIDS stigma and discrimination was conducted, and in that study they mentioned the key goal of all research should be to contribute to the development of programs and policies aimed at effectively reducing the human suffering (both in terms of new infections and in terms of the quality of life for people with HIV disease as well as those considered to be at risk of infection) that is a direct

\footnotetext{
* Corresponding author: Indian Institute of Public Health, Hyderabad, Telangana State, India.

E-mail addresses: suneetha@iiphh.org (S. Pendyala), melissa.g@iiphh.org, melissa.g@iiphh.org (M.G. Lewis).
} 
result of unmitigated HIV and AIDS-related stigmatization and discrimination. ${ }^{9}$ According to the new Elsevier report global trends research on HIV/AIDS, team from Elsevier's Analytical Services analyzed research in HIV field that was published between 2014 and 2018 states that HIV/AIDS incidence rate began to decline. ${ }^{10}$ However; there were no studies in Andhra Pradesh that assessed stigma among HIV patients. Hence, the aim of the study was to study about stigma among HIV patients and to assess the role of ICTC in addressing stigma among them.

\section{Methods}

\subsection{Study design}

Mixed methods study.

\subsection{Study population}

HIV positive patients, ICTC counselors, and medical officer.

\subsection{Study setting}

Government General Hospital, Guntur, Andhra Pradesh.

Patients visiting the ICTC centre were interviewed about stigma using a questionnaire consisting of 33 items. This questionnaire was created using the International Centre for Research on Women (ICRW) guidelines. A qualitative approach was adopted by a combination of indepth interviews and un-structured dialogues to assess the role of ICTC in addressing stigma. Counselors, along with medical officer, were interviewed. The sessions were audio recorded after obtaining verbal consent. An interview guide was developed for the counselors and medical officer about the role of ICTC in addressing stigma among HIV positive patients. The interviews were conducted at the hospital. Only one moderator was involved, and the interviews were conducted with a mixture of two languages, (English and Telugu). Adequate flexibility was given to the topic guide during the process of an interview, which included further probing or omitting specific topics depending on how the patient responded.

The quantitative data was entered in Microsoft Excel and the qualitative data in Microsoft Word. Descriptive statistics, i.e., frequency and percentages, were reported for categorical variables and Mean \pm standard deviation was reported for continuous variables. The interviews were transcribed in English; themes were identified and coded. The codes were assigned to facilitate natural consolidation of responses, and coding was performed. Ethics was obtained from Indian Institute of Public Health Hyderabad.

\section{Results}

\subsection{Quantitative study results}

A total of $54 \mathrm{HIV}$ positive patients visiting the ICTC centre were identified during the period from August 1 to August 31, 2017. An equal number of males and females (27 males and 27 females) were included. Out of the total, $46.3 \%$ were illiterates, $25.9 \%$ had completed primary education, HIV patients who completed their secondary education were $13 \%, 11.1 \%$ had completed senior secondary, only $3.7 \%$ had completed their graduation. There was only one student who was 16 years old. Based on the occupation status, it was found that most of them $(75.9 \%)$ were private workers. $20.4 \%$ were housewives, $14.8 \%$ were private workers and $1.9 \%$ were business owners and a student. The mean age was 36.17 years with a standard deviation of 9.91. Table 1 provides the Demographic details of the patients included in the study. Figs. 1 and 2 displays the education and occupation status of HIV patients.
Table 1

Demographic details of the HIV Positive patients.

\begin{tabular}{lll} 
Variables & Categories & Frequency (\%) \\
\hline Age & & $36.17 \pm 9.91^{\mathrm{a}}$ \\
Sex & Males & $27(50 \%)$ \\
Education profile & Females & $27(50 \%)$ \\
& Illiterate & $25(46.3 \%)$ \\
& Primary & $14(25.9 \%)$ \\
& Secondary & $7(13.0 \%)$ \\
Occupation & Senior Secondary & $6(11.1 \%)$ \\
& Graduation & $2(3.7 \%)$ \\
& Private Worker & $41(75.9 \%)$ \\
Family History of HIV & House wife & $11(20.4 \%)$ \\
& Business & $1(1.9 \%)$ \\
& Student & $1(1.9 \%)$ \\
& No & $54(100 \%)$
\end{tabular}

${ }^{\text {a }}$ Mean \pm Standard deviation.

\subsection{Stigma among HIV patients}

In the present study, stigma among HIV patients was categorized into six domains (Fig. 3), they are.

- Social judgment

- Anticipated stigma

- Internalized stigma

- External stigma

- Discrimination

- Resilience

Social Judgment Stigma - 29\% of HIV patients felt shameful because of their HIV status and could not associate with the community.

Anticipated stigma- It is the fear of negative corollaries if a person knew about the HIV status, it was found that $33.3 \%$ of HIV patients feared about how other people (friends, family, employer, or community) would respond about their HIV status. They also feared about them being gossiped. The fears of being physically harassed or threatened verbally were some of the negative stigmas that they faced.

Internalized stigma- These had negative beliefs and feelings. They experienced feelings of guilt, shame, low self-esteem, and also blamed themselves/others.

Experienced stigma- Despite the HIV status, most of the HIV patients $(94.44 \%)$ did participate in social gatherings or activities. Very few patients excluded from the social gatherings because of the people aware of their HIV status.

Resilience - Resilience is about resisting stigma and discrimination experienced. $75 \%$ of HIV patients did not provide emotional, physical or referral support to others who were tested HIV positive; this is because they were not emotionally healthy to support others who were suffering from the same. However, they all received support from the ICTC counselors. ${ }^{11}$

Discrimination- Other than HIV status, $15.4 \%$ of HIV patients were mistreated because of discrimination. The reasons for discrimination were, sexual orientation, injecting drug user, migrant worker, sex worker, refugees, internally displaced person, member of an indigenous group or prisoner. ${ }^{12}$

\subsection{Level of satisfaction of ICTC services}

The percentage of patients aware of the ICTC services was $96.30 \%$. Two people who were not aware of ICTC services were a student and a driver. 54\% of HIV patients said that the lab results provided by ICTC were useful in overcoming problems and were satisfied with the services provided by the ICTC. Only $2 \%$ of the patients said that they faced problems at the time of counselling (regarding gender). Table 2 displays the results of the items regarding ICTC and its services. 


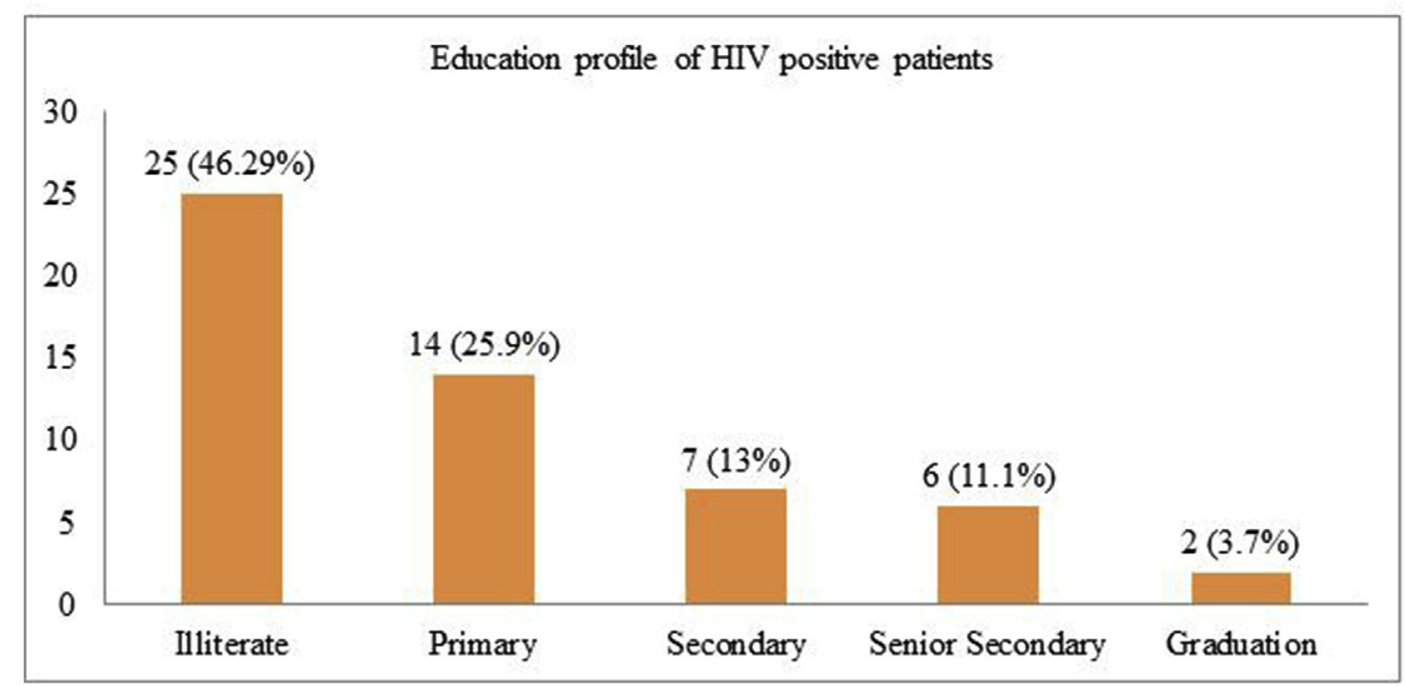

Fig. 1. Displays the education profile of HIV patients.

The in-depth interviews were conducted among HIV patients and summarized into three themes, they are, 1) Services provided in ICTC 2) Perceptions of People living with HIV and 3) Attitude about the ICTC services.

\subsubsection{Services provided to the HIV positive patients}

Three ICTC counsellors and a medical officer at ICTC were interviewed. These counsellors provide Pre-test counselling for every HIV patient. Every patient visiting ICTC for the first time, was briefly described regarding the testing, and is sent to the lab. If the person was tested positive; post-test counselling was given and was referred to the Anti-Retroviral Therapy Centre for medication. Time taken for pretest counselling was around $10 \mathrm{~min}$; posttest counselling was between 20 and $30 \mathrm{~min}$. The ICTC provided posttest counselling for approximately 16 HIV patients per week.

Counsellor 1- "Regarding the services of ICTC: family counselling, partner counselling and suicide counselling to the HIV positive patient is must and should" (Respondent Id-participant1, female, semi-structured interview).

Counsellor 2- "According to 90-90-90 rule for every HIV positive patient medication should be given and sputum examination will be done through ICTC" (Respondent Id-participant2, male, semi structured interview).

Counsellor 3- "NGOs are providing some awareness camps regarding discrimination for HIV patients" (Respondent Id-participant3, male, semistructured interview).

\subsubsection{Perceptions of people living with HIV}

According to the counsellors, most of the patients do not speak at the Centre during their first visit. However, gradually, they open up about their condition at home or work. At the initial stages, the patients do feel ashamed of their status, and step by step, they feel accepted. Proper diet and regular exercise for HIV patients can lead a normal and healthy life. Awareness and counselling are essential for family members of HIV positive patients so that they should not get discriminated by the family members.

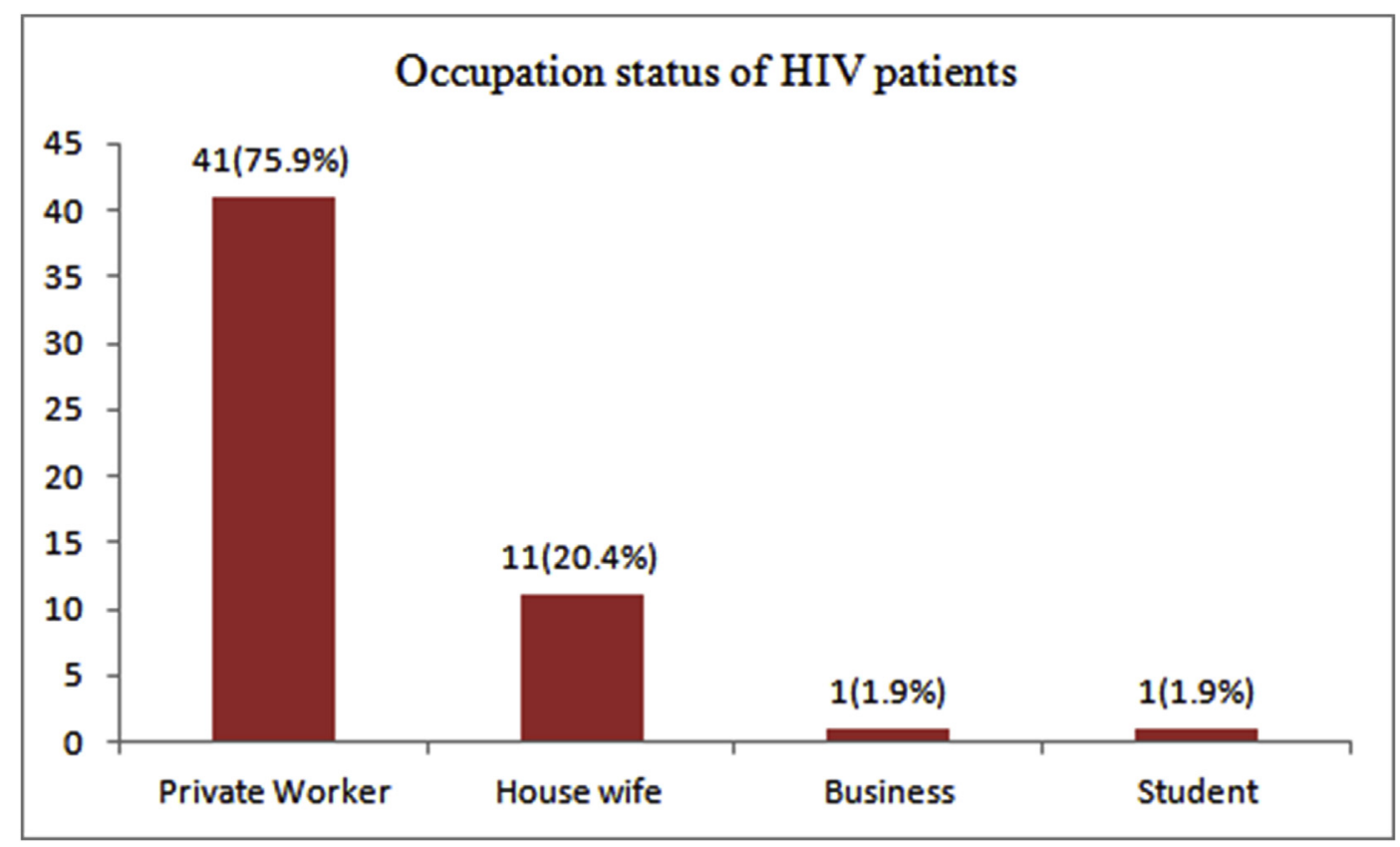

Fig. 2. Displays the occupation status of HIV patients. 


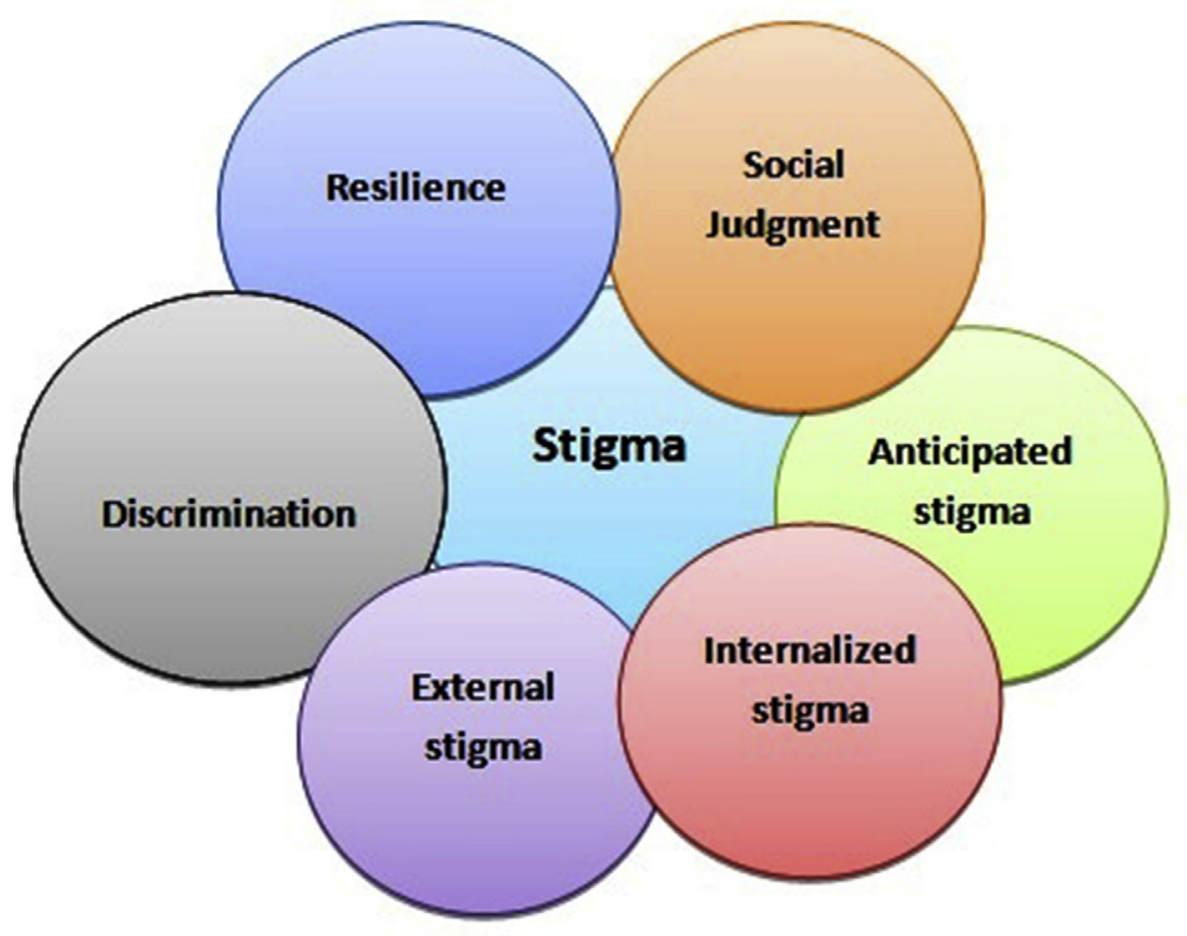

Fig. 3. Types of stigma among HIV patients.

Counsellor 1- "Awareness camps, programmes through ANMS and Anganwadi workers have been conducted to reduce stigma in HIV positive patients" (Respondent Id-participant1, female, semi structured interview).

Counsellor 2- "I will disagree that people living with HIV should feel ashamed of themselves because medicines are available at ART Centre." As a human being, everyone will get diseases, and instead of feeling bad about that disease it is better to take medicine, proper diet and physical activity that can help to live a healthy life" (Respondent Id-participant2, male, semistructured interview).

Counsellor 3- "First we should educate and bring awareness in family members about HIV so that discrimination can be reduced in HIV positive patients" (Respondent Id-participant3, male, semi-structured interview).

\subsubsection{Attitude about ICTC services}

According to the counsellors, services provided to the HIV positive patients by the ICTC counsellors were very useful. None of the health workers in ICTC spoke inappropriately about the people living with HIV. For better implementation of ICTC services, quality of counselling should be needed through more refresher training to the counsellors with lab results.

Counsellor 1- "I think financial help should be provided (like loans) for the poor HIV patients so that they will not depend on others" (Respondent Idparticipant1, female, semi-structured interview).

Counsellor 2- "For better implementation of ICTC services some refresher training are needed and ICTC infrastructure should be changed in a corporate level" (Respondent Id-participant2, male, semi-structured interview).

Counsellor 3- "For better implementation of ICTC services online registration should be maintained and patients should be provided ART medicine at their convenient places the counsellors should be patience towards HIV positive patients at the time of counselling" (Respondent Id-participant3,male, semi-structured interview).

\section{Discussion}

Stigma is a social construction which dramatically affects the life experiences of the individuals infected with the human immunodeficiency virus. The study aimed at assessing stigma among HIV patients and the role of ICTC in addressing HIV/AIDS-related stigma. 54 HIV + patients attending the ICTC government general hospital at the Guntur district in Andhra Pradesh were included. There was no age or gender as the inclusion criteria. The participants were selected based on convenience sampling. The quantitative questionnaire for assessing stigma consisted of closed-ended items and was developed based on the guidelines provided by the ICRW. A total of 40 questions/items were included. Out of which, 33 items were related to stigma, and the remaining 7 items were related to services provided by the ICTC. Each question had two options, either yes or no. Prior to the study, the questionnaire was validated by subject experts for its content and relevance. Seven patients were included in the pilot study for testing the

Table 2

Displays the frequency and percentages of items regarding ICTC and its services.

\begin{tabular}{|c|c|c|}
\hline Sl No & Items & $\mathrm{F}(\%)$ \\
\hline 1 & Were the counselling provided by ICTC is useful in overcoming problems (stigma)? & $53(98.15 \%)$ \\
\hline 2 & Are you aware of the ICTC services? & $52(96.30 \%)$ \\
\hline 3 & Are you satisfied with the services provided by the ICTC? & $54(100.00 \%)$ \\
\hline 4 & Do you face any problems related to ICTC counsellors (regarding gender) to take counselling? & $2(3.70 \%)$ \\
\hline 5 & Do you expect any services other than counselling? (HIV patients are willing to take medications at ICTC only instead of going to ART centre) & $36(66.67 \%)$ \\
\hline 6 & Do the staff at ICTC expecting any fare from you (to keep the information confidential)? & $0(0.00 \%)$ \\
\hline 7 & Were the lab results provided by ICTC is useful in overcoming problems? & $54(100.00 \%)$ \\
\hline
\end{tabular}


questionnaire.

In this study, stigma was categorized into 6 domains out of which internalized stigma was found to be prevalent among HIV patients. The HIV patients with internalized have low self-esteem, feel guilty about the HIV status and these patients were not getting proper support from their family members. A similar result was obtained in 2002 study in New York. ${ }^{13}$

As there were only three counselors (two males and one female) and one female medical officer in the hospital, we included all of them for the qualitative study. It was seen that the patients were satisfied with the female counsellor than the males. All the patients agreed that the ICTC services were useful in addressing HIV/AIDS stigma. The lab results provided by the ICTC were very accurate and satisfied.

The strengths of study are 1) This was the first study conducted in Andhra Pradesh on assessing stigma among HIV patients. 2) In addition, assessing the role of ICTC in addressing stigma was also uniquely done in this study.

The limitations of the study are 1) The results obtained from both the objectives may not be generalized to the entire state due to the fact that the ICTC Centre was selected based on the convenience of the researcher. 2) The questionnaire used in this study was not tested for reliability.

\section{Conclusion}

The study identified that internalized stigma is more prevalent among HIV patients because of lack of family support to the HIV patients resulting in feelings of guilt, shame, low self-esteem. Counselling provided at the ICTC to the HIV patients was beneficial but needed more refresher training for the counsellors for a better quality of counselling and awareness creation sessions for the family members.

\section{Declaration of competing interest}

There are no conflicts of interest.

\section{Acknowledgments}

We thank the support provided by the Indian Institute of Public
Health, Hyderabad and the Government General Hospital at Guntur to carry out this research.

\section{References}

1. HIV Facts \& Figures. National AIDS Control Organization | MoHFW | GoI. . [Internet]. [cited 2020 Apr 20]. Available from:. http://naco.gov.in/hiv-facts-figures.

2. Guntur tops the list of HIV positive cases in Andhra Pradesh | Hyderabad News Times of India [Internet]. . [cited 2020 Apr 20]. Available from:. https:// timesofindia.indiatimes.com/city/hyderabad/Guntur-tops-the-list-of-HIV-positivecases-in-Andhra-Pradesh/articleshow/45838621.cms.

3. HIV/AIDS. . [Internet]. [cited 2020 Apr 20]. Available from:. https://www.who.int/ news-room/fact-sheets/detail/hiv-aids.

4. WHO/Europe. Mental health - stigma and discrimination [Internet]. . [cited $2020 \mathrm{Apr}$ 20]. Available from:. http://www.euro.who.int/en/health-topics/noncommunicablediseases/mental-health/priority-areas/stigma-and-discrimination.

5. Integrated Counselling and Testing Centre. National AIDS Control organization | MoHFW | GoI. . [Internet]. [cited 2020 Apr 20]. Available from:. http://naco.gov.in/ integrated-counselling-and-testing-centre.

6. Vlassoff C, Weiss MG, Rao S, Ali F, Prentice T. HIV-related stigma in rural and tribal communities of Maharashtra, India. J Health Popul Nutr. 2012 Dec;30(4):394-403.

7. Steward WT, Bharat S, Ramakrishna J, Heylen E, Ekstrand ML. Stigma is associated with delays in seeking care among HIV-infected people in India. [Internet]. $J$ Int Assoc Phys AIDS Care. 2013;12(2):103-109 Mar 26 [cited 2020 Apr 20]. http://www. ncbi.nlm.nih.gov/pubmed/22282878.

8. Dasgupta Sharoda, Sullivan Patrick S, Dasgupta Aparajita, Saha Bibhuti, Salazar Laura F. Stigma and access to HIV care among HIV-infected women in Kolkata, West Bengal. . [Internet]. [cited 2020 Apr 20]. Available from:. https://journals.sagepub. com/doi/full/10.1177/1545109711401410; 2013.

9. Parker R, Aggleton P. HIV and AIDS-related stigma and discrimination: a conceptual framework and implications for action. Soc Sci Med. 2003 Jul 1;57(1):13-24.

10. New Elsevier report charts global trends in HIV/AIDS research [Internet]. . [cited 2020 Apr 20]. Available from:. https://www.elsevier.com/connect/new-elsevierreport-charts-global-trends-in-hivaids-research.

11. Stangl AL, Brady L, Fritz K. Measuring HIV Stigma and Discrimination Figure 1. Reducing HIV Stigma and Discrimination. A Framework for Programme Implementation and Measurement Vii Among the Actionable Drivers and Facilitators, Key Conceptual Domains for Measurement Include: • Fear of Infection through Casual Contact with People Living with HIV • Social Judgment, Including Shame, Blame, Prejudice and Stereotypes • the Legal and Policy Environment. Stigma Impacts [Internet]. . 2012; 2012. [cited 2020 Apr 20]. Available from:. www.stigmaindex.org.

12. What is discrimination? . EOC [Internet]. [cited 2020 Apr 20]. Available from:. https://www.eoc.org.uk/what-is-discrimination/.

13. Lee RS, Kochman A, Sikkema KJ. Internalized stigma among people living with HIVAIDS. AIDS Behav. 2002 Dec;6(4):309-319. 